\title{
EL SENADO COMO CÁMARA DE REPRESENTACIÓN DE INTERESES. UNA PROPUESTA NO ORTODOXA ${ }^{1}$
}

\author{
MANUEL RAMÍREZ JIMÉNEZ \\ Catedrático de Derecho Político \\ Universidad de Zaragoza
}
SUMARIO
I. El senado o el problema de nunca aca- bar: Breve alusión jurídico constitucional.
II. La propuesta de una Cámara federal y su actual imposibilidad.
III. La solución como Cámara representativa de intereses: una propuesta heterodoxa.

\section{EL SENADO O EL PROBLEMA DE NUNCA ACABAR: BREVE ALUSIÓN HISTÓRICO-CONSTITUCIONAL}

Jugamos con lo de "nunca acabar" porque, en efecto, desde que se aprobó nuestra actual Constitución de 1978 se anda dando vueltas al tema. Bien pronto nació la afirmación de que, tal como está regulado y, además, con la actual Ley Electoral por medio, el Senado se mostraba como una Cámara que, pese a ser conocida como Alta, para bien poco servía. Y, desde entonces, una y otra vez, el problema del Senado y la pregunta de qué hacer con él, está en el aire. No solamente entre la comunidad de constitucionalistas, sino también entre la clase política y la propia ciudadanía, a esta desazón por la escasa importancia, se ha unido un largo rosario de proyectos de nueva regulación que han acabado en la nada. Unas veces por comodidad gubernamental y otras por intereses de partidos. Modificar la estructura del Senado significaba, de entrada, cambiar la Ley a través de la cual son elegidos sus miembros. Ardua labor que todos prometen pero que luego olvidan. Y acaso es que llevara razón el maes-

1 Una primera versión de este texto, ahora retocada, constituyó el tema de una conferencia pronunciada en la Real Academia de Ciencias Morales y Políticas. 
tro Sánchez Agesta cuando afirmaba que ningún partido que ha llegado al poder con una determinada ley electoral, buena o mala, se lanza luego a su reforma. También puede darse el caso que sea un partido el que, de una u otra forma, tenga mayoría en la Cámara de los Diputados, y otro (que constituye la oposición) la tenga el Senado. El problema, en estos casos, se agrava. ¡Nadie quiere poner en riesgo el lugar en el que posee su parcela de poder!

Por unas razones o por otras, lo cierto es que nuestro actual Senado produce la impresión, nada gratuita, de escaso valor en sus funciones. Como el lector habrá ya adivinado, lo que sigue viene a constituir la exposición de dos posibles salidas al problema. Con muy poco entusiasmo por la primera y con mayor énfasis en la segunda. Sin duda porque es la segunda en la que más creo, a pesar de su carácter "heterodoxo". Es decir, por su alejamiento de otros bien diferentes planteamientos y, por qué no decirlo, por el riesgo de mala interpretación.

Pero antes de entrar en el breve desarrollo de ambas, estimo que bien merece la pena el recordatorio de nuestro pasado. $\mathrm{O}$, a mejor decir, de lo que ha sido y para qué ha servido el Senado en nuestra nada escasa historia políticoconstitucional. Como casi siempre suelo hacer, permítame el lector que ofrezca esta referencia en forma de síntesis. Al cabo, son reflexiones sobre el ayer. Si bien en nuestro país, aunque se diga o se haga lo contrario, el ayer parece que no termina nunca de serlo. Casi siempre acaba condicionando el hoy, el presente.

Desde esta premisa que entiendo puede dar cierta luz al problema, me parece que pueden ser perfectamente válidas las tres afirmaciones que siguen:

a) El Senado, en buen tracto de nuestra historia, para lo que ha servido es para dar cobijo a sectores o estamentos propios del Antiguo Régimen. De ahí el carácter conservador que acaba suponiendo. O de otra forma dicho, cuando se articula la configuración del Nuevo Régimen, agotada la vigencia de la Constitución de 1812, no se ocultan dos cosas. Primero, que "hay que seguir teniendo en cuenta" a los protagonistas del pasado que, por demás no se resignan tan fácilmente a su completa desaparición ni a la pérdida de su influencia. Como decimos, es lo que ocurre tras la efectiva vigencia de "la Pepa". Aunque ésta, «la Pepa gaditana" esté durante lustros en el deseo de muchos, dentro y fuera de España. Desde el Estatuto Real, con otra denominación, en adelante, el Senado aparece integrado por representantes de la jerarquía de la Iglesia, de la Nobleza, del Ejército o de altas instituciones culturales del Estado. Y en la mayoría de los casos, esta presencia se debe a la libre y directa designación del Rey, que también mantiene su parte de soberanía. Y segundo, en estos casos lo que se quiere evitar es un absoluto poder legislativo de la llamada Cámara baja, elegida por los ciudadanos, bien a través del sufragio restringido, bien a través del sufragio universal (ya avanzada la Restauración y por supuesto con la práctica del caciquismo siempre por medio). Hacía falta un órgano corrector de los posibles "excesos" de esta segunda Cámara y para eso estaba el Senado. 
b) En Senado, en otros supuestos, ha venido a constituir un órgano de mera consulta o de simple segunda lectura para realizar funciones correctivas de escaso alcance. Estaba ahí, integrado de una u otra forma, para "un repaso" de lo salido del Congreso, mejora en las formas de redacción o perfeccionamiento de estilo. Menesteres bastante secundarios y con muy poca importancia en el proceso legislativo. Todo lo más, en algunos casos, con iniciativa limitada a una materia muy concreta. Puede que, salvando todo lo salvable, uno de esos casos sea el de nuestro actual Senado, por más exaltaciones que del mismo se hayan realizado en estos últimos años.

c) Curiosamente, el Senado aparece o desaparece de los textos constitucionales, según el carácter de momento histórico de que se trate. O de otra forma dicho, en las ocasiones de auténtica ruptura con el inmediato pasado se prescinde de la figura del Senado. Estamos, como ejemplos, en la Constitución de 1812, que rompe con el pasado de la soberanía regia, o en la Constitución de la Segunda República Española (1931). La razón que se esgrime es bien clara: una e indivisible es la soberanía, una es la nación y, por ende una tiene que ser también la Cámara que a ambas representa. Por el contrario, el Senado aparece o reaparece en los momentos de continuidad, no de ruptura. La dicotomía reforma-ruptura que preside nuestra última transición quizá sea la causa de la actual problemática del Senado, sobre todo por el carácter muy singular de un Estado compuesto por Comunidades Autónomas, pero sin llegar a ser un Estado Federal. Y de aquí, igualmente, el hecho de que cuando el Senado iba a tener un auténtico sentido era en el Proyecto de Constitución de la Primera República Española, de carácter federal. Decimos "iba a tener" porque, como es sabido, dicho Proyecto no llegó a convertirse en Constitución por el pronto y trágico final de aquél régimen. El caballo de Pavía entrando en las Cortes puso fin al evento, por lo demás también pronto caído en el siempre peligroso cantonalismo. De todas formas recordemos que el Proyecto, por primera vez en nuestra historia política hablaba de una entidad "compuesta", si bien dicha entidad nunca dejó de llamarse Nación, algo muy conveniente de recordar en los momentos en que estos párrafos se redactan. Decía el Proyecto: "Componen la Nación española los Estados de..." Y se pasaba a enumerar a todas las regiones entonces existentes, incluyendo todavía, como parte de la Nación, al "Estado de Cuba". Si hacemos su lectura desde nuestros días, amén de lo chocante que resulta llamar Estado a Murcia, por ejemplo, no lo es menos la proclamación de dos Estados para Andalucía: Andalucía Alta y Andalucía Baja ¡Cualquiera se atrevería ahora a realizar tal distinción entre dos Andalucías! El más duro de los anatemas caería sobre su cabeza. Y, naturalmente, como siempre que se rompe el principio y el federalismo viene de arriba, no resulta nada fácil poner luego unos límites por todos aceptados. En pleno cantonalismo, el Gobierno de Madrid (¡Madrid siempre culpable de todo!) se vio en la necesidad de sofocar al Cantón de Cartagena a base de cañonazos. Y es que ipor qué Cartagena iba a pertenecer a Murcia? Antes que eso, la muerte o el "asilo" en los Estados Unidos de Norteamérica. Es el gran peligro de nuestra secular insolidaridad y del federalismo realizado al revés. Otra lección a tener siempre presente. 
Pero terminando este breve excursus por el pasado que siempre enseña, vayamos al presente del problema.

\section{LA PROPUESTA DE UNA CÁMARA FEDERAL Y SU ACTUAL IMPOSIBILIDAD}

La aspiración a convertir nuestro Senado en Cámara Federal parece ser la primera posible solución citada. A veces se suaviza la expresión y se habla, casi con timidez que no merma lo arriesgado del empeño, de "federalizante", en vez de federal. Evidentemente, esto supone una falta de rigor considerable por muy usadas que sean expresiones similares (Comité Federal de un Partido, Comisión Federal). Se juega a colar ideológicamente lo federal en un Estado que no lo es.

Va de suyo que aspirar a un Senado federal conlleva tener un Estado federal, una estructura federal del todo. Y esto, hoy por hoy, no existe.

Sintetizando bastante el fondo del problema (el del Estado-Senado federal), me atrevería a afirmar que estamos ante algo constitucionalmente imposible, políticamente inútil y democráticamente peligroso. Diré algo sobre cada una de estas tres afirmaciones.

\section{a) Constitucionalmente imposible}

Sencillamente, ni en la letra ni en el espíritu de nuestra actual Constitución tiene cabida la fórmula federal. Por más vueltas que se dé y por mucho que se quiera "estirar" la comprensión del vigente diseño del no menos equívocamente llamado "Estado de las Autonomías".

Ante todo, España queda definida constitucionalmente como un único Estado ("Social y democrático de Derecho"), frente al supuesto de un conjunto de Estados que se unen dando paso a algo superior (la Unión, la Federación, la Confederación, etc.) propia del esquema federal. Esto está muy claro en el primer artículo de nuestra Ley de Leyes.

En segundo lugar, la soberanía nacional reside en el pueblo español (art. 2) como un todo indivisible. Y ello frente al proceso de cesiones del parcelas de soberanía también a favor de algo superior, que es el camino recorrido por los actuales Estados federales. Desde el punto de vista constitucional (otra cosa son las aspiraciones ideológicas no contenidas en el texto), ni hay Estado Federal, ni hay Nación de naciones.

Por eso, en nuestro actual modelo autonómico, las competencias se han cedido o transferido del Estado español que ya existía (y que, por cierto, no ha nacido ayer) a las Comunidades Autónomas, expresión de claro compromiso político pero tampoco exenta de cierta equivocidad ( $¿ y$ como se puede ser a la vez autónomo de y parte de, ya que las Comunidades Autónomas también son Estados?). Igualmente, por eso las Cortes Generales de la nación han tenido y siguen teniendo la última palabra en todo el proceso descentralizador: desde la aprobación de los Estatutos de Autonomía hasta sus posibles reformas. 
Dejo ahora al margen la triste realidad de que, si el federalismo ha solido tener históricamente (salvo en los actuales ejemplos europeos de falsos federalismos basados en la vis coactiva de un partido-ejercito dominante: la antigua URSS o la ex-Yugoslavia), un afán integrador y se ha hecho de abajo a arriba, en nuestra historia política ha ocurrido justamente lo contrario. Quizás tenga algo que ver en ello la tendencia "localista" de nuestro federalismo histórico, compartido, curiosamente por movimientos tan ceñidos a nuestro acaecer hispano como ha sido el anarquismo.

Sigo afirmando que no es un Estado Federal ni un Estado plurinacional lo que se quiso por nuestros constituyentes, a pesar de la introducción del término "nacionalidades", por cierto insólito en nuestra historia constitucional: ni la segunda República llegó a emplearlo nunca. Quizás porque, al tratarse de algo indefinido e impreciso, se queda a camino entre la región y el Estado y acaba por no decir nada. De ahí su actual desuso.

Lo que ocurre es que este único Estado se autodefine compatible (art. 2) con nacionalidades y regiones "que lo integran. Es decir que integran algo que ya existe previamente, como no podía por menos de reconocerse, y que no se crea ex novo en 1978. Es el mismo sentido que posee el art. 137 que abre el famoso Título VIII: "El Estado se organiza territorialmente en municipios, provincias y en las Comunidades Autónomas que se constituyan. Es decir, vuelve la referencia a algo que ya existía y que ahora lo que puede tener es una nueva "organización" (retorno un segundo atrás: el Título I de la tan "rotamente condenada" Constitución de 1931 no tenía empacho en llamarle "organización nacional»). Y frente a eso que ya existía, lo nuevo, lo que puede ser, son precisamente las Comunidades Autónomas que se constituyan. No olvidemos que, en principio, unas podrían constituirse y otras, no. Lo de la hemorragia autonómica vino después, en parte por razones políticas y en parte por lo que en otro lugar he denominado presencia o aparición del "regionalismo visceral".

En suma, un Estado y, con él, un Senado federal, supone lisa y llanamente una nueva Constitución. Con el riesgo que ello comporta y a lo que volveremos luego. Lo cierto es que se fletó este nuevo diseño, probablemente huyendo de las dos experiencias históricas anteriores. Me refiero al final cantonalista de la Primera República o a la crispación social de la autonomía como excepción que es lo que, en el fondo, estaba en la mente de los constituyentes de la Segunda República. Tengo para mí que estamos ante una asignatura todavía pendiente, a pesar de la buena voluntad de quienes partearon el texto. Entre lo que dice la Constitución y esta aspiración, legítima pero contradictoria con ella, media un abismo.

\section{b) Políticamente inútil}

Las soluciones lo son en verdad y resultan útiles en su ensayo si arreglan problemas. Y ahí voy. La introducción, a estas alturas, de un Estado-Senado federal, me temo que no solventaría nada en el duro trance de nuestro secular "problema regional". Me referiré a esta inutilidad, con algunas preguntas que lanzo al lector. 
¿Solventaría la creación federal la tan, al parecer, irrenunciable demanda del derecho a la autodeterminación? Algo que ya quedó claro durante el proceso de creación constitucional mediante el intento de un Título VIII bis en el que claramente se concebía este derecho, en el supuesto de que cupiera entre nosotros, como paso a la creación de un Estado independiente. No me detengo aquí en lo que en otro lugar he estudiado con minuciosidad ${ }^{2}$. Contesto sencillamente, no.

¿Solventaría dicha creación la aspiración, más o menos explicitada y con mayor o menor violencia, a la independencia? Sencillamente, no.

¿No parece una constante histórica la pretensión de toda nación a convertirse en Estado, a crear su propio Estado? Véanse los actuales conflictos europeos y extraeuropeos para contestar: desde los kurdos hasta los palestinos.

Por eso hablo de un paso políticamente inútil. Sencillamente, la vuelta a Rousseau y, sobre todo, la imposibilidad argumental de poner el fin. ¿Quién lo pone y con qué argumentos? La apelación a "lo diferencial" vale para todo, acaso porque la igualdad hace mucho tiempo que tiene sus campos: igualdad ante la ley, igualdad de oportunidades, no segregación precisamente por o en función de lo desigual. Lo mismo que no hay nadie exactamente igual a otro, tampoco hay una comunidad, del alcance que sea, exactamente igual a otra. Y, al menos personalmente, sigo valorando con sumo mimo la gran conquista histórica del Estado moderno. Allá cada cual con su discrepancia y las consecuencias que de ella se deriven.

\section{c) Democráticamente peligroso}

Era la tercera y última afirmación antes de pasar página. Y vuelvo al recurso de las preguntas.

El paso al Estado federal ¿sería aceptado por todos? ¿Habría pleno acuerdo entre instituciones de derecho y fuerzas de hecho? ¿Y qué clase de Estado federal? A esta última pregunta he oído contestar con la original respuesta de un "Estado federal asimétrico". Burdo eufemismo para no decir desigual. Es decir, permanecería el problema al haber eso que ahora se llamaría Estados de primera y Estados de segunda. Y recomenzaría lo del agravio comparativo y la mayor o menor vigencia del "hecho diferencial".

Pienso que esto puede ir mucho más allá y llegar hasta la misma situación en que sería el régimen, no ya la forma de Estado, la que podría cuestionarse. Parece fuerte, pero así lo creo: sería un momento muy delicado para nuestra todavía juvenil democracia, sometiéndola a una prueba demasiado difícil.

Téngase en cuenta que lo que ahora tenemos es obra de una etapa de difícil consenso al que se llegó por la coincidencia de muy diversos factores sobre los cuales también he reflexionado por escrito no hace mucho ${ }^{3}$. Desde la exis-

2 MANUEL RAMÍREZ, Partidos y Constitución. Un estudio de las actitudes parlamentarias durante el proceso de creación constitucional, Centro de Estudios Constitucionales, Madrid, 1989.

3 MANUEL RAMÍREZ, Reflexiones sobre la transición de la democracia" en Educación a Distancia. Madrid. 1990. 
tencia de la sociedad con potente clase media enemiga de cualquier riesgo. Una Monarquía recién instaurada que supo conectar con ese sentimiento. Me temo que la moderación de entonces, el sacrificio que por doquier se hizo en aras a una ideal común llamado democracia, la sensatez de los líderes políticos y sindicales del momento, etc, son factores muy difícilmente repetibles en los momentos actuales en los que se rezuma más dosis de disenso que de consenso.

No podemos estar continuamente "inventando" el estado. Preguntándonos cada mañana qué clase de Estado somos y queremos. Esto es inconcebible o especialmente chocante en un país pionero en la construcción de la unidad nacional. Sería caer en el eterno partir de cero de nuestra historia político-constitucional, llena de bandazos y de ocasiones perdidas.

Por ello hay siempre que llamar a la meditación y al sosiego a quienes, desde el olvido o la insensatez, se empeñan, de vez en vez, en ponerlo todo patas arriba. Posiblemente desde su legítima parcela de verdad. Pero sin deparar en que cualquier aspiración, por legítima que sea, debe acabar en ese peligroso punto en que pone en peligro serio e irreparable la no menos legítima aspiración a la libertad de los demás. En esto y en todo. No nos lancemos a la aventura de destruir la obra sin tener la plena seguridad de su utilidad política. Y, sobre todo, la plena certeza de que, al hacerlo, no se tambalean, no se ponen en solfa los cimientos de una pacífica convivencia en democracia tan largamente deseada.

De aquí, y a ello íbamos, el rechazo a esta primera avenida por la que podría correr la reforma de nuestro senado. Salvo que caigamos en la ironía de repetir que se es lo que no se es. Es decir, hablar de un Senado federal en un Estado que no es Federal. Para ello, sobran las alforjas. Si se trata de jugar con palabras o, incluso, de cambiar nombres, de eso estamos ya al cabo de la calle. Y posiblemente sean las calles las que más sepan de lo que quiero decir, si se me permite la ironía. Pero si lo que queremos es abordar en serio el problema, la "utopía federal" queda invalidada para nuestro Senado. Pasemos a la segunda opción.

\section{LA SOLUCIÓN COMO CÁMARA REPRESENTATIVA DE INTERESES: UNA PROPUESTA HETERODOXA.}

La segunda avenida por la que puede correr la reforma de nuestro Senado y por la que inclino mi preferencia personal, al menos como seria posibilidad para someter a estudio, sitúa a la segunda Cámara en un reflejo de nuevo pluralismo característico del moderno Estado Social de Derecho.

No voy a cansar al lector con la exposición detallada de las notas que han sido descritas como constitutivas de esta clase de Estado: predominio del ejecutivo, trsalado del locus en que fundamentalmente se toman las decisiones políticas, auge de la Administración, etc. Todas ellas han sido paradigmáticamente estudiadas por autores como Ernst Forsthoff ${ }^{4}$, y, entre nosotros, por el

4 El Estado en la sociedad industrial, Madrid, 1975. 
gran maestro Manuel García Pelayo5. A los efectos que hoy nos preocupan retengamos estas dos.

En primer lugar, el auge de la realidad del llamado Estado de las Asociaciones (Verbändestaat). Al pluralismo tradicional que encarnaban los partidos, hay que unir actualmente un llamado nuevo pluralismo organizacional constituido por la infinita gama asociativa que el moderno Estado y la moderna sociedad están conociendo. El hombre ya no está en el juego social y político únicamente en el viejo concepto de ciudadano, sino que a ello (y a veces con mayor relieve)une su condición derivada de ese grupo social en que desarrolla su vida. Y así, actúa y se comporta en tanto que funcionario, trabajador, empresario, pensionista, ecologista, etc. Una rica y viva red de asociaciones que pueblan el actualmente llamado tejido social o, quizá con menos precisión, sociedad civil. Hay que contar con el protagonismo de este mundo asociativo que deviene factor esencial de nuestra hora.

Ocurre, además y como inciso, que este auge asociativo está coincidiendo con dos defectos harto señalados de los partidos políticos. Nos referimos, ante todo, a la propia deficiencia representativa de unos protagonistas, los partidos, que campean por el llamado mundo occidental bajo la etiqueta de partidos cógelo-todo. Se han hecho notables renuncias ideológicas y, por el contrario, se amplia el abanico de ofertas por que la clientela política potencial es toda la nación. Sus programas electorales caen en la más palpable ambigüedad y el votante acaba optando en atención a un líder. De esta evolución en España me he ocupado en un libro al que ahora remito ${ }^{6}$. Y, por otra parte, a estos protagonistas le ha aquejado en nuestro país demasiado pronto, el también conocido proceso de oligarquización interna. Algo que choca con nuestro mandato constitucional y que está convirtiendo la vida interna de nuestros partidos en algo rígido, carente de debate, mundo de filias y fobias y, por todo ello, difícil cauce para representar y encauzar los auténticos intereses y problemas de la sociedad. Diríamos que a esta crisis de los partidos en todo lo que no signifique su propio funcionamiento como máquinas electorales (papel último en el que resultan insustituibles en la democracia de nuestro siglo), está correspondiendo, como consecuencia, el auge y protagonismo de la red asociativa: desde los colegios profesionales al mundo sindical, desde los grupos pacifistas a las entidades en defensa de los consumidores. Diría más. Si allá por los años sesenta lo que podía predicarse de nuestro país era una debilidad notoria de este mundo asociativo, frente al ejemplo de su riqueza en el mundo anglosajón, algo que ya señalara Tocqueville para el otro de océano, no creo equivocarme al anunciar que ha cambiado radicalmente el panorama y que el españolito de a pie está teniendo mucha más confianza en el grupo al que cotidianamente pertenece que en el partido al que de tarde en

5 Las transformaciones del Estado contemporáneo, Madrid, 1977.

6 MANUEL RAMÍREZ, Sistema de partidos en España (1931-1990), Centro de Estudios Constitucionales. Madrid. 1991. 
tarde vota. Y ello tanto en lo que hace referencia a su representación, como a la defensa de sus intereses. Pero dejemos ya el inciso, que venía a ser complementario.

La segunda característica que queríamos destacar del moderno estado Social que analizamos es la importancia de lo que se conoce como consulta a los interesados. Se llega a hablar de la actual democracia de codecisión. Y la trama argumental parece obvia. Si de verdad se quiere que una decisión política sea eficaz y perdure, parece incuestionable la necesidad de cierto consenso previo con aquellos sectores a los que afecta. Política por consenso, frente a la política por imposición, incluso si ésta viene dada por la legítima vía de las mayorías parlamentarias.

Oír, negociar y tener en cuenta antes de tomar la decisión es algo que convertirá la opción política a tomar en algo más sólido y duradero, menos dependiente de vaivenes temporales o acomodo de coyunturas.

Este protagonismo, conocido en la ciencia política norteamericana como corporatismo, por supuesto ajeno al viejo corporativismo de los regímenes autoritarios y divulgado entre nosotros por Salvador Giner, entre otros ${ }^{7}$, no excluye el imprescindible papel de los partidos, ni rompe el principio democrático al que luego aludiremos. Habla, simplemente, de tener presente ese mundo asociativo antes referido y de su papel en la sociedad actual. En la compleja sociedad actual.

Más aún, Hans Peter Schneider, en su obra "Democracia y Constitución" ${ }^{8}$ ha ido mucho más allá, y ha apelado, en la actual democracia, a la necesidad de amplio consenso a la hora de adoptar las por él denominadas "decisiones de nuevo tipo". Las de consecuencias irreversibles. Las que requieren algo más que el acuerdo mayoritario de un momento dado, en función de su propia importancia (alianzas en política exterior, política de medio ambiente, política educativa, etc). Son decisiones llamadas a resistir el paso de tiempos y generaciones y que por demás, tienen muy difícil vuelta atrás. $\mathrm{O}$, al menos, la rectificación resulta profundamente costosa y perjudicial. El veredicto de Schneider es claro: hay que pasar de la democracia de la opinión a la democracia de codecisión. La que no es sólo democracia representativa y de partidos. La que también es de intereses afectados y apela a su consulta. Aquí está el esbozo de este nuevo pluralismo del que venimos hablando en esta segunda perspectiva.

La articulación de todo esto no creo encontrarla en el diseño de nuestra democracia vigente en España, emanada del texto de 1978. Sabido es que primaron el papel y función de los partidos políticos. Algo sin duda necesario en el momento constituyente y tras largos años de condena oficial. Los partidos

7 XAVIER ARBÓS y SALVADOR GINER, La gobernabilidad. Ciudadanía y democracia en la encrucijada mundial, Ed. Siglo XXI. Madrid. 1993.

8 "Soberano sin poder", Representación y participación del pueblo como problema de legitimación de la soberanía democrática, Centro de Estudios Constitucionales, Madrid, 1991, págs 249 y ss. 
tomaron la hegemonía representativa y de participación. El artículo 6 de nuestra Constitución nos exime de mayor comentario. Ha sido más tarde cuando esta hegemonía se ha evidenciado defectuosa e insuficiente por causas ya aludidas. Y el resto de los foros citados por la constitución me parecen o desarticulados, aislados y con peso muy circunstancial (por ejemplo los colegios profesionales, las asociaciones de empresarios o los mismos sindicatos); o escasamente aludidos por el texto o, en fin, con alcance meramente consultivo. Es el ejemplo, por no extendernos, en el detalle, del Consejo económico y social que, ya por su misma ubicación constitucional ${ }^{9}$ tiene un ámbito muy distinto, especialmente previsto para la planificación económica, con limitada composición y, sobre todo, carácter meramente consultivo. ${ }^{10}$

Y si esta articulación no existe, si la laguna está ahí y, sobre todo, si la empresa se acomete sin romper el método democrático al que de inmediato vamos a ocuparnos, ¿por qué no orientar la reforma del Senado hacia una Cámara representativa de este nuevo pluralismo que en ella expongan y defiendan sus intereses? Ejemplos hay en el Derecho Constitucional Comparado y, a mi entender, incluso algún ingrediente de modernización puede suponer nuestra demasiado clásica democracia representativa. Sin dañar a la democracia y sin menosprecio de las tareas fundamentales de los partidos, se trataría de un Senado entendido como Cámara colegisladora y participativa, con presencia de esa riqueza asociativa (Universidad, Ejército, Empresarios, Sindicatos de trabajadores, Academias, Colegios Profesionales, asociaciones voluntarias de peso nacional..., etc.). Lo que hoy está fuera de partidos y de mayorías y no debe seguir así.

Claro que la gran pregunta es el como ¿Cómo llevar a cabo esa integración sin afectar a la democracia, que todo lo demás debe resultar secundario?

La empresa es lo que suficientemente arriesgada y difícil como para ensayar aquí y a estas alturas de mi excursus los detalles del proceso. Me limitaré a afirmar que el cómo supone o conlleva tres supuestos básicos, desde los que empezar a reflexionar y caminar después.

1. ${ }^{\circ}$ La desmitificación de la carga igualitarista de nuestra actual democracia. Me explico. Ciertamente, en la comprensión científica e ideológica del auténtico sentido de la democracia se han dado corrientes claramente diferenciadas. Por un lado, la que podríamos llamar continental, de cuna francesa, que tiende a considerar el principio democrático como algo mas, como mucho más que una mera forma de gobierno. Según ésta corriente, hay que ver a la democracia como una auténtica filosofía política, como una forma de vida, como un talante de ser, casi como una religión (es la posición de autores tales como Lacroix y Burdeau, por ejemplo). Lo de método y forma de gobierno sería hasta secundario. De ahí el valor de una socialización política en democracia y mi reiterada afirmación de que no hay democracia sin demócratas, que no nacen, sino

9 Título VII. Economía y Hacienda.

10 Artículo 131. 
que se hacen ${ }^{11}$. Sin duda esta concepción es la que llega hasta los protagonistas de nuestra segunda República, que siempre tendieron a identificar República con Democracia y hasta a la ingenuidad política de la célebre frase de Jiménez de Asúa: «Si la República no hubiera venido a mudarlo todo, no merecería la pena haberla traído". Como si desde un texto constitucional se pudiera mudarlo todo y, además, como si de verdad hace falta esa mudanza absoluta cuando adviene un nuevo régimen. Parto de lo contrario: incluso la izquierda tiene que procurar conservar cosas, valores, tradiciones, etc. Consustanciales a la forma de ser o al sentido histórico de una nación o de un pueblo. Por otro lado, la corriente norteamericana (quizá anglosajona)de limitar el sentido de la democracia a mero método político basado en los supuestos de participación, representación y control. Lo que importan son las bases estructurales para que esas tres "esencias"se produzcan. Y por eso el sistema educativo de la Gran Bretaña no tiene nada de democrático, ni el sistema económico norteamericano nada de igualitario.

Pues bien, entre nosotros ocurre que la idea y la práctica de la democracia se vienen uniendo a una especie de "igualitarismo a la baja". Y así, en un órgano de gobierno de una Universidad, los alumnos y los miembros del Personal de Servicios votan igualitariamente si se debe conceder o no a una figura académica el título de "Honoris Causa". Me limito a este ejemplo que bien conozco. Llegando al absurdo podríamos hasta votar igualitariamente si a la hora de una intervención quirúrgica, la hace el cirujano especialista o el celador del hospital o si, a la hora de dar la orden de ataque militar lo hace el general o la suma de votos de los soldados. Entiendo que este llamado igualitarismo (como hemos indicado antes, ajeno a la igualdad de oportunidades, la igualdad ante la ley o la no discriminación) tiene bien poco que ver con la democracia en cualquiera de las dos corrientes expuestas. Si nos olvidamos de él, se salvará lo esencial de la democracia y de la representación. Y a lo que íbamos. En una Cámara (Senado) puede haber una representación de rectores de universidad perfectamente democrática en la medida en que sean rectores elegidos por los Claustros de sus centros y no designados por el Ministerio. O de Decanos de Colegios Profesionales libremente elegidos. O de Secretarios de Sindicatos también libremente elegidos. Se salva el principio, que es lo que importa y ya la Cámara será, a no dudarlo, plenamente representativa del tejido social. Algo para pensar aquí y ahora.

2. ${ }^{\circ}$ La reforma de la actual Constitución. No me extiendo sobre este punto porque ya ha sido aludido. Cualquier reforma del Senado pasa por ahí y por la consiguiente reforma de la ley electoral. Y no hay que asustarse. Tanto menos cuanto que el actual Senado ha demostrado ya plenamente que así debe ser, como, muy posiblemente, todo lo que hay tras el Título VIII de nuestra vigente Constitución hace tiempo que esté ya puesto en cuarentena.

11 MANUEL RAMÍREZ, "La socialización política en España. Una empresa para la democracia". Revista Sistema, n. ${ }^{\circ}$, enero, 1980. 
3. ${ }^{\circ}$ Recuperación del consenso perdido. Sin esto no vamos a ninguna parte. Para reformar el Senado y para reformar la Constitución. Es preciso volver, como sea, al consenso mayoritario de los años iniciales de nuestra democracia. Y no lanzarse a empresas desde lo contrario, desde el disenso. Me consta la dificultad de la empresa, sobre todo porque el peligroso tema regional, al que, a diferencia de la frase orteguiana, no hay que "conllevar", sino, algo muy distinto, "Convivir" e "integrar"; se quiso deliberadamente cerrarlo de alguna manera. Si el consenso no existe, la fórmula que proponemos está llamada al fracaso, como presumo que todas las demás.

Sentados estos tres puntos de partida, importa menos la minucia del cómo, que puede tener muchas vías y hasta distintas fases. Lo que me importaba es dejar ante la atención del lector esta posible solución al tema de nuestro senado, solución que, por supuesto, a muchos parecerá heterodoxa. Y eso, por lo menos, es lo que pienso.

ABSTRACT. The author starts analysing the effect and meaning that the existance of the Senate has had in the political and constitutional history of Spain, pointing out its clearly conservative nature and its sense of second chamber merely corrective purposes of the legislative task coming out from the Chamber of Deputies. Nowadays, when the subjet of its possible reform is raised again, the author discards the possibility of it being converted in a federal institution, sometting that would be incompatible with the Constitutional regulation in use. In the presence of this, the author bets for its conversion in a representative Chamber of interests of the various sectors of society, chosen democratically, and with the need of implanting the actual practice of politics among us, based on co-decission, being previously consulted to the affectes members. 